\begin{tabular}{l} 
JOURNAL OF EMPOWERMENT \\
VOL. 2, No. 2, Desember 2021, h.162-171 \\
ISSN 2580-0620 (Print) \\
ISSN 2597-9809 (Online) \\
Available Online at https://jurnal.unsur.ac.id/index.php/JE \\
\hline \hline
\end{tabular}

\title{
WORKSHOP KINEMASTER BAGI GURU UNTUK MENINGKATKAN KUALITAS VIDEO PEMBELAJARAN
}

\section{KINEMASTER WORKSHOP FOR TEACHERS TO IMPROVE THE QUALITY OF LEARNING VIDEO}

\author{
1Selvi Riwayati, ${ }^{2}$ Ristontowi, ${ }^{3}$ Yuriska Destania, ${ }^{4}$ Nyayu Masyita Ariani, \\ 5 Risnanosanti, ${ }^{6}$ Masri, 7 Mardiah Syofiana \\ 1234567Universitas Muhammadiyah Bengkulu \\ riwayatselvi@gmail.com, tontowi1966@gmail.com,yuriskadestania@yahoo.com \\ nyayu.masyita@gmail.com risnanosanti@umb.ac.id, masritan@gmail.com, \\ sofya203@gmail.com
}

\begin{tabular}{|l|l|l} 
Masuk : 06 Juni 2021 & Penerimaan : 06 November 2021 & Publikasi : 31 Desember 2021
\end{tabular}

\begin{abstract}
ABSTRAK
Keterbatasan pengetahuan, skill, dan pelatihan merupakan salah satu faktor kurangnya minat tenaga pengajar yaitu guru dalam memanfaatkan alat peraga berbasis TIK pada proses pembelajaran di kelas. Tujuan pelatihan ini yaitu agar guru termotivasi untuk memperbaiki kinerja, cara pembelajaran atau menambah wawasan keilmuan seorang guru. Metode kegiatan ini berupa sosialisasi dan workshop pembuatan bahan ajar berbasis TIK dengan menggunakan Aplikasi KineMaster. Kegiatan ini dilaksanakan di SMP Negeri 18 Kota Bengkulu. Kegiatan ini diikuti oleh 15 orang guru dari berbagai mata pelajaran seperti Matematika, IPA, Bahasa Indonesia, Bahasa Inggris dan guru BK. Evaluasi dilakukan melalui Aplikasi Zoom yang melibatkan seluruh peserta guru SMP Negeri 18 Kota Bengkulu. Pelatihan dan pendampingan pembuatan bahan ajar berbasis TIK tidak hanya dilakukan melalui tatap muka, tim pengabdian juga menjelaskan kepada mitra untuk dapat berkonsultasi dengan menggunakan telpon dan aplikasi Whatsapp. Hasil dari kegiatan pengabdian agar guru dapat membuat video pembelajaran beranimasi dengan menggunakan Aplikasi KineMaster.
\end{abstract}

Kata Kunci : Guru; KineMaster; Pembelajaran; Sekolah; Video.

\begin{abstract}
Limited knowledge, skills, and training are one of the factors for the lack of interest in teaching staff, namely teachers in using IT-based teaching aids in the learning process in the classroom. The purpose of this training is to motivate teachers to improve performance, learning methods or add scientific insight to a teacher. The method of this activity is in the form of socialization and workshops on making ICT-based teaching materials using the KineMaster Apk. This activity was carried out at SMP Negeri 18 Bengkulu City. This activity was attended by 15 teachers. The evaluation was carried out through the Zoom application which involved all teacher participants of SMP Negeri 18 Bengkulu City. The result of this service activity is that teachers can create animated learning videos using the KineMaster Apk.
\end{abstract}

Keywords : Teacher; KineMaster; Learning; School; Videos.

\section{A. PENDAHULUAN}

Matematika adalah ilmu yang bermanfaat di berbagai lini kehidupan, dan matematika sebagai salah satu mata pelajaran yang memiliki sistem sangat teratur dan terstruktur dapat dijadikan salah satu penerapan model pembelajaran yang relevan saat ini (Dewi et al., 2014). Mulai dari pertanian, perikanan, arsitektur, hingga ilmu tentang antariksa membutuhkan matematika. 
Mata pelajaran matematika sudah diajarkan sejak dari taman kanak-kanak, SD, SMP, SMA hingga perguruan tingggi sehingga pengajaran matematika membutuhkan cara yang berbeda-beda sesuai tingkat usia anak. Matematika yang bersifat abstrak merupakan ilmu yang sulit dipelajari bagi sebagian orang (Depdiknas, 2002). Oleh karena itu, dibutuhkan alat bantu yang mampu mempermudah proses pembelajaran tersebut. Salah satu alat bantu tersebut adalah penggunaan alat peraga baik itu manual maupun yang berbasis TIK. Alat peraga berfungsi mengkongkritkan fakta-fakta agar lebih jelas dan mudah diterima oleh siswa.

Survei di SMP N 18 Kota Bengkulu yang berjarak 7,8 KM dari Universitas Muhammadiyah Bengkulu menunjukkan bahwa hanya sebagian kecil tenaga pengajar yang memanfaatkan IT sebagai alat bantu proses pembelajaran di kelas, selebihnya masih menggunakan pembelajaran yang masih bersifat tradisional tanpa menggunakan alat bantu terutama pembelajaran matematika. Ketika anak diajarkan dengan alat bantu berupa video pembelajaran, anak terlihat begitu semangat jika bibandingkan dengan yang tidak menggunakan alat peraga, anak terlihat monoton dalam proses pembelajaran.

Kondisi seperti di atas bukan tidak disadari oleh pihak sekolah sebagai penyelenggara pendidikan, namun keterbatasan pengetahuan, skill, dan pelatihan merupakan salah satu faktor kurangnya minat tenaga pengajar yaitu guru dalam memanfaatkan alat peraga berbasis TIK pada proses pembelajaran di kelas. Hal ini senada dengan (Fajar et al., 2017), menyatakan komputer sudah tersedia di setiap sekolah dan software mudah diperoleh namun sumber daya manusia dalam hal ini guru kurang mampu dalam menggunakannya dengan baik untuk proses pembelajaran maupun proses evaluasi pembelajaran maka perlu dilakukan upaya untuk meningkatkan kompetensi guru melalui pelatihan pembelajaran berbasis TIK. Pernyataan ini juga di dukung oleh penelitian (Abdul Syukur, 2014) menunjukan bahwa $62,15 \%$ guru jarang menggunakan TIK dalam pembelajaran, 34,95\%, guru kurang menguasai teknologi informasi dan komunikasi, 10,03\% sarana dan prasarana kurang mendukung. Hal ini juga ditambah dengan kondisi dunia yang sedang dilanda pandemic covid 19, yang memaksa semua sektor terutama pendidikan, mau tak mau harus melaksanakan pembelajaran daring (dalam jaringan) yang tentunya harus menggunakan TIK sebagai fasilitas pembelajaran. Di lain pihak keterbatasan ilmu pengetahuan, skill di bidang TIK salah satu menjadi masalah dalam pelaksanaan pembelajaran daring tersebut. Hal ini juga ditambah sebagian guru sudah termasuk katagori yang tak muda lagi menyulitkan mereka untuk beradaptasi dengan perkembangan IPTEK.

Data menunjukan bahwa Indonesia masih tertinggal jauh dari negara ASEAN lainnya. Banyak faktor penyebab rendahnya kualitas pendidikan, salah satunya faktor kualifikasi guru dan belum sesuainya bidang ilmu yang dimiliki (Indriani, 2015).

Dari permasalahan di atas, perlu untuk meningkatkan kompetensi guru dengan melaksanakan kegiatan pelatihan. Adapun pelatihan yang dilaksanakan di SMP Negeri 18 Kota Bengkulu yaitu pelatihan pembuatan bahan ajar berbasis TIK yang lebih difokuskan cara penggunaan Aplikasi KineMaster dalam membuat bahan ajar beranimasi.

Dari hasil analisis terhadap permasalahan utama yang dihadapi mitra di atas, maka solusi dari permasalahan mitra yaitu peningkatan mutu guru dari segi kompetensi guru dan harus sesuai standarisasi guru di tiap jenis dan jenjang pendidikan sekolah (standar kompetensi). 
Kompetensi guru dapat ditingkatkan melalui program pelatihan dalam jabatan (in service training). Adapun tujuan dilaksanakan pelatihan yaitu agar guru termotivasi untuk memperbaiki kinerja, cara pembelajaran atau menambah wawasan keilmuan seorang guru. Menurut Center for Development Management and Productivity (Depdiknas, 2002) mendefinisikan pelatihan yaitu belajar untuk mengubah tingkah laku orang dalam melaksanakan pekerjaan mereka. Dengan demikian pelatihan dapat diartikan sebagai suatu proses memberikan bantuan bagi para guru untuk memperbaiki kekurangan dalam melaksanakan proses pembelajaran.

Banyak sekali media pembelajaran yang dapat digunakan guru untuk menunjang proses pembelajaran demi meningkatkan kompetensi seorang guru, salah satunya adalah pembuatan animasi dengan menggunakan aplikasi KineMaster. Hal ini senada dengan (Mahendra \& Minarsih, 2020) bahwa pemanfaatan pengelolahan video di handphone seperti aplikasi KineMaster dapat membantu guru dalam menciptakan video bahan ajar yang menarik bagi siswa. Pemanfaatan komputer sebagai media pembelajaran merupakan salah satu solusi yang tepat untuk mewujudkan pembelajaran yang mandiri melalui bahan ajar yang diprogram secara interaktif. Salah satu media pembelajaran yang dapat menjelaskan materi matematika bersifat abstrak dan terkesan menarik yaitu powerpoint. Aplikasi powerpoint menjadi salah satu media pembelajaran yang dibuat tidak hanya didominasi tulisan tetapi mengganti penjelasan materi dengan tulisan singkat, dan animasi untuk visualisasi kondisi (Astuti et al., 2020). Pembelajaran berbasis multimedia (teknologi yang melibatkan teks, gambar, suara, dan video) mendukung pembelajaran abad 21, yang memusatkan pembelajaran pada siswa (student center) (Astuti \& Bhakti, 2018). Animasi media pembelajaran Power Point diharapkan dapat membantu meningkatkan pemahaman sekaligus prestasi belajar siswa.

Media pembelajaran merupakan segala sesuatu yang dapat menjadi sarana perantara; berupa sumber belajar yang instruksional untuk memfasilitasi komunikasi dalam pembelajaran sehingga tercipta lingkungan belajar yang kondusif (Azhar, 2016; Munadi, 2013).

Aplikasi KineMaster merupakan salah satu aplikasi untuk pembuatan bahan ajar berbasis TIK yang mudah digunakan. Hal ini senada dengan hasil peneltian (Widiono, 2021) menyatakan pengetahuan tentang Aplikasi KineMaster dari mahasiswa sangat tinggi $82 \%$, pembuatan media pembelajaran melalui Aplikasi KineMaster mudah diterapkan mahasiswa sejumlah 63\%, kesulitan yang dihadapi dalam penggunaan KineMaster dalam hal pengembangan materi mencapai $38 \%$, kemudahan mahasiswa mahasiswa dalam menampilkan video di LSM sejumlah $63 \%$ dan hasil persentase kebermanfaatan penggunaan Aplikasi KineMaster bagi pembelajaran IPA sejumlah $89 \%$ dengan tingkat manfaat $76-100 \%$. Dengan demikian penerapan Aplikasi KineMaster dapat digunakan dalam pengembangan materi dan bahan ajar bagi dosen, guru dan mahasiswa dalam proses kegiatan pembelajaran.

(Darnawati et al., 2021) juga menyatakan ada hasil positif dari kegiatan pelatihan pembuatan video pembelajaran menggunakan Aplikasi KineMaster dan screencast o matic dalam hal peningkatan daya saing dan tata nilai dalam bidang pendidikan pada binaan mitra. Peningkatan kemampuan para dosen muda dalam menggunakan teknologi dan informasi dalam kesehariannya untuk mengajar. Hal ini bisa dibuktikan dengan setelah pemaparan materi, peserta diberikan kesempatan untuk praktik membuat video pembelajaran secara berkelompok dan individu dengan menggunakan Aplikasi KineMaster dan 
screencast o matic. Dari kegiatan tersebut, 70,6\% mereka beranggapan puas terhadap kegiatan ini dan berharap ada kegiatan pelatihan kembali.

Berdasarkan dari hasil penelitian dan pengabdian diatas maka, tujuan hasil kegiatan pengabdian ini adalah sebagai berikut:

1. Adanya peningkatan kapasitas kompetensi para guru dalam memahami bagaimana mensinergiskan proses pembelajaran matematika dan pembuatan bahan ajar berbasis TIK terutama pemanfaatan Aplikasi KineMaster.

2. Adanya peningkatan kemampuan para guru dalam menggunakan Aplikasi KineMaster.

3. Memotivasi para guru dalam menyelesaikan berbagai masalah pendidikan.

4. Membatu guru dalam membelajarkan matematika yang bersifat abstrak agar mudah dipahami oleh siswa.

\section{B. METODE}

Metode yang dilakukan dalam pelatihan pembuatan bahan ajar berbasis TIK yaitu dengan cara memberikan pelatihan langsung. Hal ini bertujuan supaya guru dapat memahami materi pelatihan dengan baik dan bias dipraktekkannya secara langsung. Langkah-langkah yang pada kegiatan pelatihan ini mengikuti alur berikut:

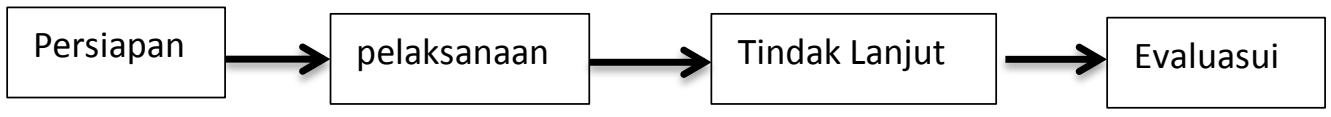

Diagram 1. Alur Kegiatan Pelatihan

1. Persiapan

a. Melakukan kontak awal dengan pihak sekolah SMP Negeri 18 Kota Bengkulu untuk menelusuri kemungkinan pelaksanaan kegiatan pengabdian masyarakat dan prosedur yang harus dijalankan berkaitan dengan pelaksanaan kegiatan, serta menentukan pertemuan awal untuk membahas kegiatan.

b. Tahap observasi berupa survey awal, melakukan pertemuan secara langsung dengan kepalah sekolah dan wakil kepala sekolah. Menelusuri lebih dalam mengenai kemmampuan para guru dalam memakai aplikasi berbasis internet.

c. Membahas hari dan tanggal pelaksanaan kegiatan

d. Mempersiapkan team yang akan memaparkan materi dan team pendamping pelatihan aplikasi.

2. Menerapkan protokol kesehatan sebelum, ketika dan sesudah melakukan pelatihan. Dalam proses pelaksanaan pelatihan para guru dengan teratur mengikuti protokol kesehatan yang sudah dibuat oleh panitia pelaksana. Dari mulai pengecekan suhu tubuh, menjaga jarak, memakai masker selama pelaksanaan pelatihan dan tidak berkumpul di satu tempat sebelumnya, ketika dan sesudah pelatihan.

3. Pelaksanaan pengabdian kepada masyarakat:

a. Perencanaan Materi, sebagai pendahuluan pada kegiatan ini, dilakukan konfirmasi terkait media yang dimiliki guru untuk dijadikan media dalam proses pembelajaran daring, apakah menggunakan HP atau laptop. Dikarenakan guru rata-rata menggunakan HP, maka sebelum menjelaskan bagaimana cara menggunakan KineMaster, para guru diminta untuk mendowload aplikasi KineMaster melalui play store. Setelah semua selesai 
menginstal aplikasi KineMaster, selanjutnya dijelaskan langkah-langkah penggunaan KineMaster.

b. Waktu dan tempat Pelaksanan, kegiatan pengabdian masyarakat ini dilaksanakan pada bulan April-Mei 2021, bertempat di SMP Negeri 18 Kota Bengkulu.

Tabel 1. Waktu dan Tempat Pelaksanaan

\begin{tabular}{|l|l|l|l|l|}
\hline \multicolumn{2}{|c|}{ Nama Kegiatan } & \multicolumn{2}{|c|}{ April } & \multicolumn{2}{|c|}{ Mei } \\
\cline { 2 - 5 } 1. Survey/cek lokasi; & Minggu 3 & Minggu 4 & Minggu 1 & Minggu 2 \\
2. Pertemuan dengan pihak & & & \\
sekolah; & & & \\
3. Permohonan izin dan diskusi \\
soal lokasi serta arahan \\
persiapan guru.
\end{tabular}

\section{Pemateri dan Pelaksana Kegiatan}

Adapun pelatihan diberikan oleh dosen Prodi Pendidikan Matematika FKIP UMB. Berikut tabel nama narasumber pelatihan kegiatan pembuatan bahan ajar berbasis TIK di SMP Negeri 18 Kota Bengkulu.

Tabel 2. Daftar Nama Narasumber dan Instruktur Kegiatan Pengabdian

\begin{tabular}{|c|l|l|}
\hline No & \multicolumn{1}{|c|}{ Nama } & \multicolumn{1}{|c|}{ Tugas dalam Tim } \\
\hline 1. & Selvi Riwayati, S.Si, M.Pd & Pemateri /instruktur \\
\hline 2. & Drs. Ristontowi, M.Kom & Pemateri/instruktur \\
\hline 3. & Yuriska Destania, M.Si & Instruktur \\
\hline 4. & Dr. Risnanosanti, M.Pd & Instruktur \\
\hline 5. & Dra. Nyayu Masyita, M.Pd & Instruktur \\
\hline 6. & Drs. Masri, M.Si & Instruktur \\
\hline 7. & Mardiah Syofianah & Instruktur \\
\hline
\end{tabular}

\section{Tindak Lanjut}

Setelah pemaparan materi tentang langka-langka pembuatan bahan ajar berbasis TIK dengan Aplikasi KineMaster, para guru diminta melakukan praktek langsung dengan didampingi oleh team pendampingan Dosen Pendidikan matematika FKIP UMB. Dalam pelaksanaan praktek tersebut para guru dapat menguasai penggunaan Aplikasi Pembelajaran, hal ini terlihat dari hasil praktek dimana setiap peserta pelatihan mampu membuat video pembelajaran sederhana yang didampingi dosen pendamping praktek. Pendampingan tidak hanya dilakukan secara langsung tetapi dilakukan secara daring via telpon maupun wa. 


\section{Evaluasi}

Seminggu setelah dilakukan kegiatan pengabdian tersebut, maka team dosen Prodi Pendidikan Matematika FKIP UMB melakukan evaluasi melaui Aplikasi Zoom yang melibatkan seluruh guru SMP Negeri 18 Kota Bengkulu.

Pelatihan dan pendampingan pembuatan bahan ajar berbasis TIK tidak hanya dilakukan melalui tatap muka pada saat Kegiatan berlangsung. Tim pengabdian juga menjelaskan kepada mitra untuk dapat berkonsultasi dengan menggunakan telpon dan aplikasi Whatsapp ketika mitra mengalami kesulitan terkait dngan pembuatan bahan ajar berbasis TIK dengan menggunakan Aplikasi KineMaster.

\section{HASIL ATAU PEMBAHASAN}

\section{Kegiatan Pelatihan}

Sebelum dilaksanakan pemaparan materi tentang aplikasi KineMaster dilakukan pretes terlebih dahulu. Hal ini dilakukan untuk mengetahui tentang pengetahuan awal yang dimiliki peserta berkaitan dengan aplikasi KineMaster. Dari hasil pretes yang dilakukan, rata-rata guru tidak mengetahui tentang pembuatan bahan ajar dengan aplikasi KineMaster. Guru-guru biasanya langsung mengambil video pembelajaran yang ada di youtube yang notabennya banyak tersedia. Pemaparan materi tentang pembuatan bahan ajar berbasis TIK dengan menggunakan aplikasi KineMaster oleh team pengabdi sebelum diadakan praktek langsung tentang pemakaian aplikasi Tanya jawab seputar aplikasi tersebut.

Pelatihan dan pendampingan pembuatan bahan ajar berbasis TIK dipilih berdasarkan pertimbangan permasalahan utama yang dihadapi mitra. Pelatihan diawali dengan memberikan penjelasan mengenai pentingnya pemanfaatan TIK dalam proses pembelajaran ditengah pandemic covid 19. Setelah diberikan penjelasan tentang media ajar berbasis TIK, selanjutnya tim memberikan penjelasan mengenai aplikasi yang sangat memungkinkan digunakan untuk membuat bahan ajar menggunakan animasi yaitu Aplikasi KineMaster yang terlihat pada gambar 1. Penggunaan aplikasi tersebut dengan berdasarkan hasil analisis tim dan beberapa pertimbangan tim yaitu aplikasi KineMaster bisa didownload melalui hp Android dan mudah dipelajari. Aplikasi KineMaster sendiri ada yang gratis da ada yang berbayar. Setelah mengenalkan Aplikasi KineMaster, selanjutnya dilakukan pelatihan langkah-langkah pembuaatan bahan ajar berbasis TIK dengan terlebih dahulu peserta pelatian mendowload Aplikasi KineMaster pada hp android masing-masing.

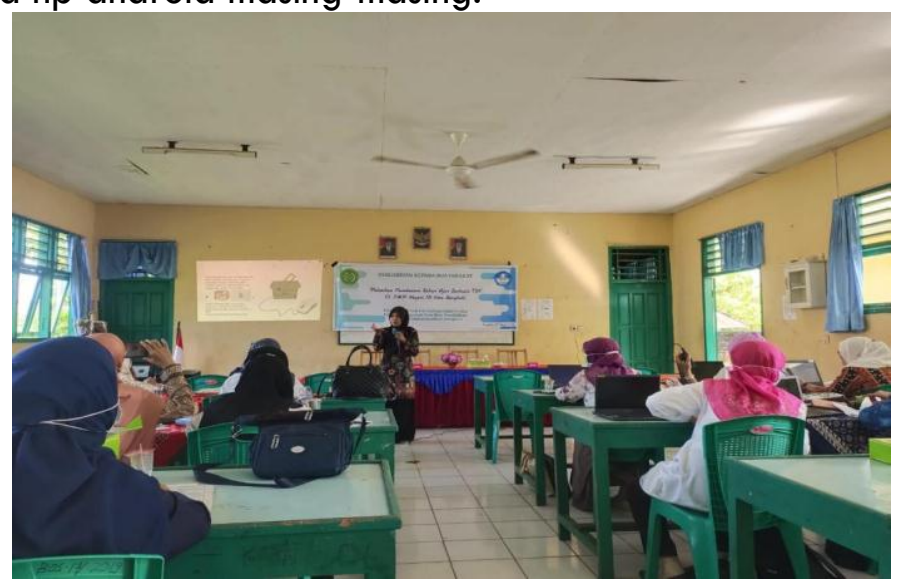

Gambar 2. Pemaparan Materi Pembuatan Bahan ajar beranimasi dengan Aplikasi KineMaster 
Setelah dilakukan pelatihan terkait dengan penggunaan KineMaster, selanjutnya dilakukan pendampingan dalam beberapa kali pertemuan untuk memastikan pembuatan bahan ajar berbasis TIK yang sudah direncanakan diawal berjalan dengan baik, serta untuk memastikan hambatan-hambatan yang ditemui para guru dalam pembuatan bahan ajar bebasis TIK dapat diselesaikan bersama dengan tim. Pelaksanaan pendampingan dalam pembuatan bahan ajar berbasis TIK dengan menggunakan Apk Kine Master di SMP N 18 Kota Bengkulu dilakukan melalui tatap muka langsung antara tim dan guru-guru bidang studi. Peserta pelatihan tidak saja dari guru bidang studi matematika tetapi guru dari mata pelajaran lain ikut serta bergabung dalam pelatihan ini.

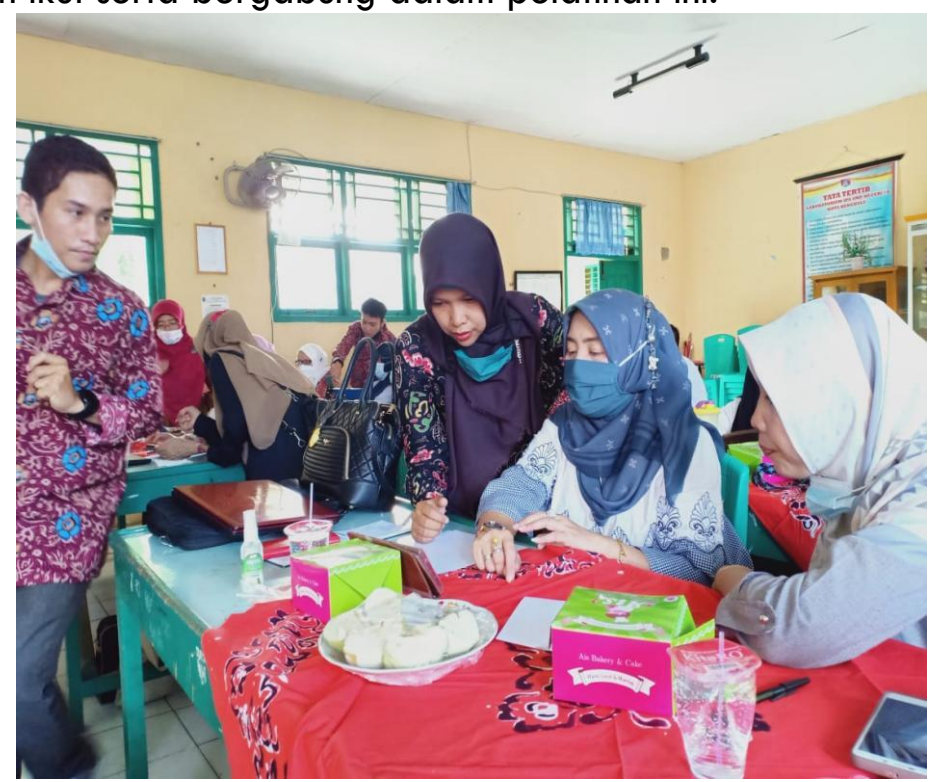

Gambar 3. Pendampingan Tim dalam Pembuatan Video Pembelajaran Sederhana

Setelah dilakukan pendampingan pelatihan pembuatan bahan ajar berbasis TIK, maka hasil bahan ajar tersebut dipersentasikan di depan. Sebagaian besar guru sangat antusias membuat video pembelajaran sederhana. Video yang ditayangkan tidak saja dari mata pelajaran matematika akan tetapi dari mata pelajaran lain juga berpartisipasi diantaranya dari guru bahasa Indonesia, IPA, Bahasa Inggris, PKn bahkan ada guru yang buat video diluar dari materi pelajaran.

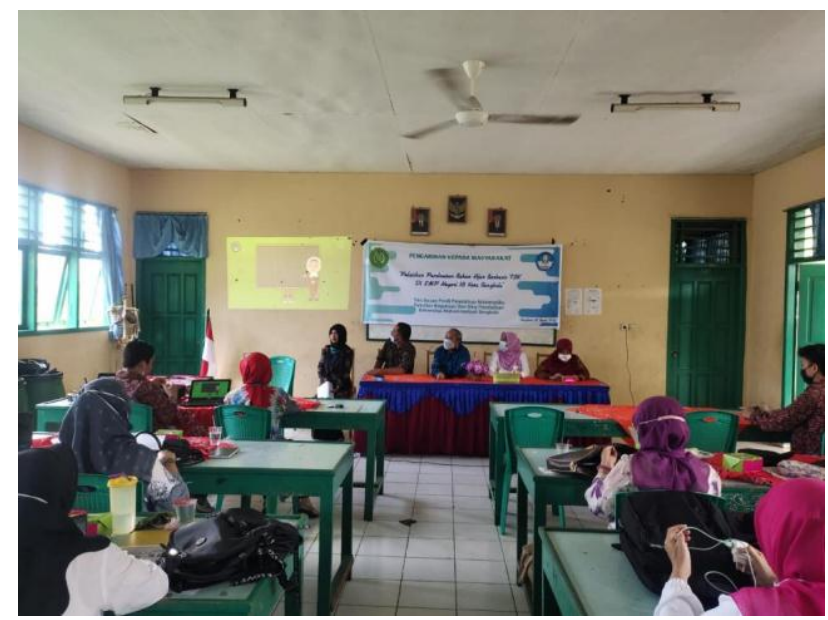

Gambar 4. Persentasi Hasil Video Pembelajaran yang Dibuat oleh Salah Satu Peserta Pelatihan 


\section{Monitoring dan Evaluasi}

Tim pengabdian sangat senang dengan respon yang diberikan mitra, dimana mitra sangat cepat memahami penjelasan yang disampaikan oleh tim pengabdian. Tidak hanya mudah memahami penjelasan, dalam proses pendampingan mitra sudah aktif mencoba-coba fitur baru yang ada di Android mereka guna mempercantik tampilan video pembelajaran beranimasi.

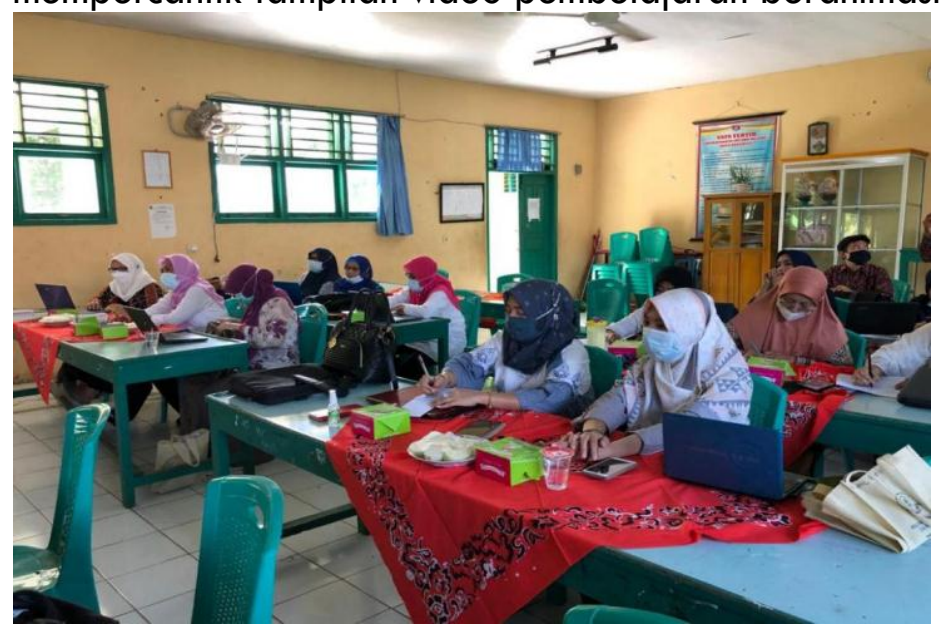

Gambar 5. Antusias Peserta Pelatihan Pembuatan Bahan Ajar Berbasis TIK

Dari hasil pengamatan dan wawancara dengan beberapa guru didapatkan kesimpulan bahwa dengan adanya pelatihan pembuatan bahan ajar berbasis TIK, mereka termotivasi untuk membuat video pembelajaran beranimasi. Hal ini terlihat dari antuasias mereka dari awal sampai akhir kegiatan.

Tingkat keberhasilan guru dalam membuat media pembelajaran menggunakan aplikasi KineMaster yaitu 78\% guru sudah mampu menyelesesaikan dengan baik pembuatan bahan ajar berbasis KineMaster dan sisanya 22\% masih kesulitan dalam pembuatan bahan ajar berbasis TIK. Persentase keberhasilan pembuatan bahan ajar berbasis KineMaster untuk guru senior adalah $57,14 \%$ sedangkan untuk guru junior $72 \%$.

\section{Kendala}

Adapun kendala yang dihadapi dalam pelaksanan kegiatan pelatihan pembuatan bahan ajar berbasis TIK yaitu rata-rata peserta kegiatan adalah guru-guru senior yang butuh waktu yang lama dalam beradaptasi dengan teknologi khususnya TIK. Untuk itu team dalam mendampingi peserta kegiatan mesti sabar dan perlahan menjelaskan setiap kegunaan tool pada Aplikasi KineMaster.

Selain itu tidak semua guru di SMP Negeri 18 Kota Bengkulu bisa mengikuti pelatihan pembuatan bahan ajar berbasis TIK. Hal ini diakibatkan oleh pandemic covid 19 yang memaksa pembatasi jumlah peserta kegiatan dan mematuhi protokol kesehatan. Kegiatan pelatiahan pembuatan bahan ajar berbasis TIK diikuti oleh 15 orang guru Mapel meliputi guru Matematika, PKn, Bahasa Inggris, Bahasa Indonesia, IPA dan BK. Peserta kegiatan sangat antusia selama mengikuti kegiatan pelatihan pembuatan bahan ajar berbasis TIK.

Tabel 2. Nama-nama Peserta Kegiatan

\begin{tabular}{|l|l|l|}
\hline No & Nama Peserta & Guru Mapel \\
\hline 1. & Kartikawati, S.Pd & IPA \\
\hline 2 & Rika Purwanti, S.Pd & Matematika \\
\hline 3 & Desmi Rohani, S.Pd & Matematika \\
\hline
\end{tabular}




\begin{tabular}{|l|l|l|}
\hline 4 & Sri Soekarsih, M.Pd & Bahasa Inggris \\
\hline 5 & Dra. Nurhasanah, M.Pd & Matematika \\
\hline 6 & Dra. Hasdelyati & Matematika \\
\hline 7 & Suryani, S.Pd & Matematika \\
\hline 8 & Parlena Suri, S.Pd & Bahasa Indonesia \\
\hline 9 & Dra. Wasro'ah & Bahasa Indonesia \\
\hline 10 & Rosmanelly, S.Pd & PKn \\
\hline 11 & Lindawati, S.H & PKn \\
\hline 12 & Delita, S.Pd & BK \\
\hline 13 & Fika Pratiwi, S.Pd & BK \\
\hline 14 & Sri Desiana, S.Pd & IPA \\
\hline 15 & Yulian, S.Pd & Matematika \\
\hline
\end{tabular}

\section{PENUTUP}

Pembuatan bahan ajar berbasis TIK dengan menggunakan Aplikasi KineMaster merupakan salah satu solusi pembelajaran dimasa pandemic covid 19. Para guru mampu dengan cepat mengikuti langkah-langkah pembuatan video pembelajaran beranimasi dengan Aplikasi KineMaster. Selain mudah dalam memahami Aplikasi KineMaster, Apk ini bias di download melalui playstore di Hp Android sehingga kapan saja dan dimana saja para guru bias membuat bahan ajar dengan Aplikasi KineMaster. Persentase keberhasilan pembuatan bahan ajar berbasis KineMaster untuk guru senior adalah $57,14 \%$ sedangkan untuk guru junior $72 \%$. Dengan demikian, penerapan aplikasi KineMaster dapat digunakan dalam mengembangkan materi dan bahan ajar bagi para guru dalam kegiatan proses pembelajaran.

Selain itu dengan adanya pelatihan seperti ini memberikan motivasi bagi guruguru senior untuk beradaptasi dengan perkembangan teknologi yang pesat. Hal ini ditambah lagi proses pembelajaran daring akibat covid 19 memaksa para guru untuk menggunakan IT dalam proses pembelajaran. Dengan pelatihan pembuatan bahan ajar berbasis TIK ini diharapkan pembelajaran menjadi semakin menarik karena materi yang disampaikan dikemas dalam bentuk animasi bergerak sehingga para siswa tidak jenuh dalam proses pembelajaran daring. Kegiatan seperti ini perlu dilakukan secara berkesinambungan dengan memanfaatkan Apk lain untuk membuat bahan ajar beranimasi demi peningkatkan profesional guru dalam proses pembelajaran.

\section{E. UCAPAN TERIMA KASIH}

Terimakasih kepada semua pihak yang terlibat baik langsung maupun tidak dalam pelaksanaan kegiatan Pelatihan Pembuatan Bahan Ajar Berbasis Tlk terutama kepada LPPM Universitas Muhammadiyah Bengkulu yang telah mendukung dalam membiayaan kegiatan ini. Dan juga kepada mitra dalam hal ini guru SMP Negeri 18 Kota Bengkulu yang memfasilitasi tempat dan mengizinkan guru-guru untuk menjadi peserta kegiatan ini. Tak lupa ucapan terimakasih kepada dosen dan Mahasiswa Prodi pendidikan Matematika Universitas Muhammadiyah Bengkulu yang berpartisipasi aktif demi lancarnya pelaksanaan kegiatan ini.

\section{F. DAFTAR PUSTAKA}

Abdul Syukur, I. (2014). Profesionalisme Guru dalam Mengimplementasikan Teknologi Informasi dan Komunikasi di Kabupaten Nganjuk. Jurnal Pendidikan Dan Kebudayaan, https://doi.org/10.24832/ipnk.v20i2.138

20(2), 200-210. 
Astuti, I. A. D., \& Bhakti, Y. B. (2018). The Effect of the Microsoft Excel based Interactive Learning Media on the Physics Problem Solving. Indonesian Review of Physics, 1(1), 7. https://doi.org/10.12928/irip.v1i1.243

Astuti, I. A. D., Dewati, M., Yona Okyranida, I., \& Asep Sumarni, R. (2020). Pengembangan Media Smart Powerpoint Berbasis Animasi dalam Pembelajaran Fisika. Navigation Physics : Journal of Physics Education, 1(1), 12-17. https://doi.org/10.30998/npipe.v1i1.191

Azhar, A. (2016). Media Pembelajaran. Rajawali Pers.

Darnawati, D., Irawaty, I., \& Uke, W. A. S. (2021). Pelatihan Pembuatan Video Pembelajaran Daring dengan Menggunakan Aplikasi Kinemaster dan Screencast O Matic. E-Dimas: Jurnal Pengabdian Kepada Masyarakat, 12 (1), 100-105. https://doi.org/10.26877/e-dimas.v1 2i 1.7204

Depdiknas. (2002). Pengembangan Kurikulum dan Sistem Pengajian Berbasis Kompetensi. Pusat Kurikulum, Balitbang.

Dewi, S. K., Suarjana, M., \& Sumantri, M. (2014). Penerapan Model Polya Untuk Meningkatkan Hasil Belajar Dalam Memecahkan Soal Cerita Matematika Siswa Kelas V. Jurnal Mimbar PGSD Universitas Pendidikan Ganesha , 2(1), 110.

Fajar, M. Y., Rohaeni, O., Permanasari, Y., A, A. I., \& Mulkiya, K. (2017). Meningkatkan Kompetensi Guru Sma Dan Sederajat Melalui Pelatihan Pembelajaran Berbasis Tik. ETHOS (Jurnal Penelitian Dan Pengabdian), 5(2), 175. https://doi.org/10.29313/ethos.v5i2.2347

Indriani, F. (2015). Kompetensi Pedagogik Guru Dalam Mengelola Pembelajaran IPA Di SD dan MI. Jurnal Fenomena, 7(1), 17-28.

Mahendra, I. K., \& Minarsih, N. M. M. (2020). Tutorial Penggunaan Aplikasi Kinemaster sebagai Pengolahan Video Pembelajaran Seni Rupa bagi Siswa Autis. Seminar Nasional Seni Dan Desain: "Reorientasi Dan Implementasi Keilmuan Seni Rupa Dan Desain Dalam Konteks Merdeka Belajar Dan Kampus Merdeka

(MBKM). https://proceedings.sendesunesa.net/id/publications/333153/tutorialpenggunaan-aplikasi-kinemaster-sebagai-pengolahan-video-pembelajaranse

Munadi, Y. (2013). Media pembelajaran sebuah pendekatan baru. Jakarta: Referensi. GP Press Group.

Widiono, A. (2021). Penerapan Aplikasi Kinemaster dalam Pembelajaran IPA melalui LMS pada Mahasiswa Prodi PGSD. Prosiding Webinar Nasional IAHN-TP Palangka Raya, 3, 12-21. https://scholar.google.co.id/citations?user= $=$ B 1 AlvoAAAAJ\&hl=id\#d=gs_md cita-

d\&u=\%2Fcitations\%3Fview_op\%3Dview_citation \%26hl\%3Did\%26user\%3D ¡B 1 AlvoAAAAJ\%26citation_for_view\%3DjB1 AlvoAAAAJ\%3A_FxGoFyzp5Q C\%26tzom\%3D420 